\title{
Myocardial dysfunction in human immunodeficiency virus infection: an echocardiographic study of 157 patients in hospital in Zimbabwe
}

\author{
J G Hakim, J A Matenga, S Siziya
}

\begin{abstract}
Objective-To determine the prevalence and characteristics of myocardial dysfunction and other cardiac manifestations in acutely ill hospital patients infected with human immunodeficiency virus (HIV) in Zimbabwe.

Design-A prospective echocardiographic survey of acutely ill HIV seropositive patients.

Setting-General medical ward, Harare Central Hospital, Zimbabwe.

Patients-One hundred and fifty seven HIV seropositive patients admitted with various acute medical conditions over a 12 month period, January to December 1994.
\end{abstract}

Main outcome measures-Detection of myocardial dysfunction and other cardiac abnormalities by cross sectional echocardiography.

Results-Eighty (51\%) men and 77 women were studied (mean (SD) age 34.4 $(8 \cdot 5)$, range $15-60$ years for males and $31 \cdot 6$ (9.0), range 16-65 years for females). They were all heterosexual. None was haemophiliac or an intravenous drug user. Echocardiographic abnormalities were found in $79(50 \%)$ patients: $14 / 151$ (9\%) had dilated cardiomyopathy, 33/151 (22\%) left ventricular dysfunction, 9/151 isolated right ventricular dilatation, and $30 / 157$ (19\%) pericardial disease (28 with effusions, three having tamponade). There were two cases of constrictive pericarditis and one of ascending aortic aneurysm.

Conclusions-There is a high prevalence of echocardiographically detected myocardial and pericardial disease in this group of acutely ill HIV infected patients. Left ventricular dysfunction without dilatation was common, but its significance was not ascertained.

(Heart 1996;76:161-165)

Keywords: echocardiography; HIV; dilated cardiomyopathy; ventricular dysfunction.

Cardiac involvement in human immunodeficiency virus (HIV) infection in Africa has mainly been attributed to pericardial disease, which is often the index presentation of patients with acquired immunodeficiency syndrome. ${ }^{1-3}$ Data on myocardial disease in HIV infected patients from Africa are scanty. In Europe and North America, necropsy reports ${ }^{45}$ and an increasing number of clinical studies $^{6-8}$ have described the presence of a wide range of myocardial involvement in various risk groups of HIV infection. Infective and non-bacterial (marantic) endocarditis have also been described in HIV infection especially in intravenous drug users. ${ }^{9}$ A prospective cross sectional echocardiographic survey was undertaken to determine the prevalence and characteristics of cardiac manifestations, especially myocardial dysfunction, in acutely ill hospital patients in Zimbabwe infected with HIV.

\section{Patients and methods}

PATIENTS

Over a 12 month period, January to December 1994, patients admitted to one of the five medical units of Harare Central Hospital with a variety of medical conditions were clinically evaluated for eligibility for entry into the study. All patients who had an illness attributed to acquired immunodeficiency syndrome, ${ }^{10}$ or had clinical features suggestive of HIV infection were eligible for entry into the study if they were HIV seropositive by a repeat enzyme linked immunosorbent assay (Abbott Laboratories, Illinois). A repeat HIV enzyme linked immunosorbent assay has been shown in our setting to have a sensitivity of $99 \%$ and specificity of $95 \%$ (Parirenyatwa Hospital HIV laboratory). CD4 lymphocyte counts were performed by a slide technique (APAAP mouse monoclonal, DAKO, Glostrup, Denmark). Patients were clinically evaluated and a thorough scrutiny of their notes including old records, outpatient cards, and referral letters was made to determine the presence of prior cardiac disease.

Patients found to have hypertension or rheumatic, ischaemic, or congenital heart disease were excluded. Women in the third trimester of pregnancy or those who had delivered within the past six months were also excluded because peripartum cardiomyopathy is common in Zimbabwe. ${ }^{112}$ Patients who were in septic shock were excluded as this has been demonstrated to cause transient decrease in left ventricular ejection fraction. ${ }^{13}$

For each patient the following information was obtained: demographic data, type of medication, and the final diagnosis on discharge or death of the patient. Every effort was made during the period of the study to include most patients admitted to the unit with an acquired 
immunodeficiency syndrome defining illness or with features suggestive of HIV infection. All subjects gave informed consent and the protocol was approved by the local ethics committee.

\section{ECHOCARDIOGRAPHIC EXAMINATION}

All patients were examined in the left lateral position with a commercially available ultrasound machine (Kretz Technik-Combison 320-5, Tiefenbach, Austria) with a $3.5 \mathrm{MHz}$ transducer. The echocardiographer was not aware of the clinical details of the patients. All patients were echogenic and had pictures suitable for analysis. Studies were recorded on Polaroid paper, $x$ ray films, and on video tape. Measurements were performed using onscreen calipers. The valves, endocardium, cardiac chambers, and pericardium were systematically examined from the parasternal, apical, subcostal, and (where indicated) suprasternal positions. Cross sectionally directed $M$ mode sections of the heart at the aortic valve level and at the level of the mitral valve tips were obtained for measurement of cardiac dimensions.

The following measurements were obtained: left atrial dimension, aortic root dimension, left ventricular end diastolic dimension (LVDd), left ventricular end systolic dimension (LVDs), right ventricular end diastolic dimension, interventricular septal wall thickness in end diastole, and left ventricular posterior wall thickness in end diastole. The conventions of the American Society of Echocardiography were followed in obtaining these measurements. ${ }^{14}$ Left ventricular fractional shortening (FS) was calculated from the formula, FS = (LVDd LVDs)/LVDd $\times 100 \%$.

The following definitions were used: isolated left ventricular dilatation-left ventricular end diastolic dimension $>57 \mathrm{~mm}$ with normal fractional shortening $(\geqslant 28 \%)$; left ventricular dysfunction-fractional shortening $<28 \%$ without left ventricular dilatation; dilated cardiomyopathy-left ventricular end diastolic dimension $>57 \mathrm{~mm}$ with a fractional shortening $<28 \%$ and global hypokinesia; isolated right ventricular dilatation-right ventricular end diastolic dimension $\geqslant 30 \mathrm{~mm}$ with normal left ventricular size and function.

STATISTICAL ANALYSIS

Measurements are given as mean (SD).

Table 1 Characteristics of HIV infected patients with cardiac abnormalities

\begin{tabular}{lrlll}
\hline & $N o$ & $\begin{array}{l}\text { Age }(y) \\
(M e a n(S D)) \\
(\text { range) }\end{array}$ & $\begin{array}{l}\text { Sex } \\
(M / F)\end{array}$ & $\begin{array}{l}\text { Alcohol } \\
\text { consumption } \\
n(\%)\end{array}$ \\
\hline All & 157 & $\begin{array}{l}33 \cdot 0(8 \cdot 8) \\
(15-65)\end{array}$ & $80 / 77$ & $75(48)$ \\
Dilated cardiomyopathy & 14 & $\begin{array}{l}31 \cdot 3(7 \cdot 2) \\
(20-42)\end{array}$ & $9 / 5$ & 7 \\
Left ventricular dysfunction & 33 & $\begin{array}{l}32 \cdot 9(6 \cdot 83) \\
(18-45)\end{array}$ & $17 / 16$ & $14(42)$ \\
$\begin{array}{l}\text { Isolated left ventricular } \\
\text { dilatation }\end{array}$ & 2 & $\begin{array}{l}36 \cdot 5(2 \cdot 12) \\
(35-38)\end{array}$ & $1 / 1$ & 1 \\
$\begin{array}{l}\text { Isolated right ventricular } \\
\text { dilatation }\end{array}$ & 9 & $\begin{array}{l}29 \cdot 0(6 \cdot 48) \\
(20-40)\end{array}$ & $6 / 3$ & 4 \\
$\begin{array}{l}\text { Pericardial disease } \\
\text { Ascending aortic aneurysm }\end{array}$ & 30 & $\begin{array}{l}30 \cdot 7(8 \cdot 33) \\
(16-45)\end{array}$ & $19 / 11$ & $17(57)$ \\
\hline
\end{tabular}

Analysis was by $t$ test for continuous variables and $\chi^{2}$ for discrete variables. A $P$ value of $<0.05$ was regarded as statistically significant.

\section{Results}

STUDY POPULATION

A total of 157 patients were entered into the study, comprising $80(51 \%)$ males and 77 females. The mean age was $34.4(8.5)$ for males (range 15-60) and $31.6(9.0)$ for females (range 16-65). All patients were heterosexual and none admitted to intravenous drug use. There were no haemophiliacs. No patient had received zidovudine or any other antiretroviral agent. The commonest diagnoses in the 157 patients were congestive cardiac failure in $37(24 \%)$, bacterial pneumonia in $22(14 \%)$, pulmonary tuberculosis in 20 (13\%), and Pneumocystis carinii pneumonia in $12(8 \%)$ patients. Only 34 patients had had a CD4 $\mathrm{T}$ lymphocyte count. The median count was $201 \times 10^{9} \mathrm{cells} / \mu \mathrm{l}$ (first quartile 99 , third quartile 417 , range $0-834)$. By the criteria of the Centers for Disease Control, ${ }^{10} 32(63 \%)$ of 51 patients with evaluable status had AIDS. Forty (25\%) of the 157 patients died in hospital. Necropsies on patients dying of natural causes are resisted culturally in this region, therefore, no postmortem studies were performed on any of those who died in this study. All patients underwent echocardiography within 72 hours of admission. One hundred and fifty one patients had cardiac chamber dimension measurements, six did not because large pericardial effusions precluded accurate measurements.

\section{ECHOCARDIOGRAPHY (TABLE 1)}

Echocardiographic abnormalities were noted in $79(50 \%)$ of the 157 patients studied, with some patients having multiple abnormalities. Alcohol consumption was similar in all groups with cardiac abnormalities (table 1). There was no evidence of rheumatic, hypertensive, congenital, or ischaemic heart disease in the study patients. One patient had an aneurysm of the ascending aorta with no evidence of cardiac dysfunction. He had a negative serological test for syphilis and did not have features of Marfan's syndrome or other similar disorder. Of the 151 patients with cardiac chamber measurements, dilated cardiomyopathy was found in $14(9 \%)$ and left ventricular dysfunction in $33(22 \%)$. In four patients (two with dilated cardiomyopathy and two with left ventricular dysfunction) single or multiple clots were seen in the left ventricular apex in association with global hypokinesia. One of the patients with left ventricular dysfunction and multiple apical clots presented with hemiplegia. Two patients had isolated left ventricular dilatation with normal fractional shortening. Right ventricular enlargement was found in $14 / 151$ (9\%) patients; nine of them had isolated right ventricular enlargement. All nine had significant pulmonary disease (empyema/ pleural effusion in three, pulmonary Kaposi's sarcoma in two, pulmonary tuberculosis in two, Pneumocystis carinii pneumonia in one, 
Table 2 Echocardiographic measurements $(\mathrm{mm})$ in HIV infected patients: comparison between those with and those without clinical features of cardiac failure and between those with dilated cardiomyopathy and those with left ventricular dysfunction (mean (SD))

\begin{tabular}{|c|c|c|c|c|c|c|c|}
\hline & \multirow[b]{2}{*}{$\begin{array}{l}\text { All } \\
(n=151)\end{array}$} & \multicolumn{3}{|c|}{ Clinical features } & \multicolumn{3}{|c|}{ Impaired LV function } \\
\hline & & $\begin{array}{l}H F \\
(n=25)\end{array}$ & $\begin{array}{l}\text { No } H F \\
(n=22)\end{array}$ & $P$ & $\begin{array}{l}\text { Dilated CMP } \\
(n=14)\end{array}$ & $\begin{array}{l}\text { LV dysfunction } \\
(n=33)\end{array}$ & $P$ \\
\hline LAD & $30 \cdot 7(6 \cdot 9)$ & $38 \cdot 6(7 \cdot 2)$ & $30 \cdot 1(4 \cdot 3)$ & $<0.001$ & $39 \cdot 6(8 \cdot 1)$ & $32 \cdot 5(6 \cdot 0)$ & 0.002 \\
\hline Ao & $30 \cdot 3(4 \cdot 7)$ & $30 \cdot 8(3.8)$ & $29.8(4.0)$ & 0.607 & $31.3(2.9)$ & $29 \cdot 9(4 \cdot 2)$ & $0 \cdot 278$ \\
\hline LVDd & $46 \cdot 7(8 \cdot 3)$ & $57 \cdot 5(7 \cdot 0)$ & $47 \cdot 2(5 \cdot 7)$ & $<0.001$ & $63.0(2.9)$ & $48 \cdot 3(5 \cdot 3)$ & - \\
\hline LVDs & $31 \cdot 6(9 \cdot 8)$ & $47 \cdot 0(7 \cdot 1)$ & $37 \cdot 2(5 \cdot 8)$ & $<0.001$ & $51 \cdot 6(5 \cdot 0)$ & $38.5(5.6)$ & - \\
\hline FS (\%) & $33 \cdot 4(11 \cdot 5)$ & $18 \cdot 0(5 \cdot 0)$ & $21 \cdot 4(4 \cdot 3)$ & 0.015 & $18 \cdot 1(6 \cdot 2)$ & $20 \cdot 2(4 \cdot 2)$ & $0 \cdot 178$ \\
\hline (range) & 6-64 & $6-26$ & $12-27$ & - & $6-26$ & $12-27$ & \\
\hline IVSTd & $9 \cdot 2(1 \cdot 6)$ & $9 \cdot 8(2 \cdot 1)$ & $9 \cdot 0(1 \cdot 6)$ & 0.153 & $9.5(1.5)$ & $9 \cdot 5(2 \cdot 1)$ & 0.940 \\
\hline LVTd & $8.8(1.5)$ & $9 \cdot 2(1 \cdot 3)$ & $9.0(1.5)$ & 0.556 & $9 \cdot 4(1 \cdot 3)$ & $8.9(1.4)$ & $0 \cdot 270$ \\
\hline
\end{tabular}

Ao, aorta; CMP, cardiomyopathy; FS, fractional shortening; HF, clinical features of heart failure; IVSTd, interventricular septal end diastolic thickness; LAD, left atrial dimension; LV, left ventricle; LVDd, left ventricular end diastolic dimension; LVDs, left ventricular end systolic dimension; LVTd, LV posterior wall end diastolic thickness; no $\mathrm{HF}$, no clinical features of heart failure.

and miliary tuberculosis in one). Four (44\%) patients with isolated right ventricular dilatation died in hospital. Pericardial disease was found in $30 / 157(19 \%)$ patients, 28 with effusions and two with pericardial thickening (one patient with pericardial thickening had constrictive pericarditis). The pericardial effusions were large (with tamponade) in three, moderate in eight, and small in 17 patients. One patient with a moderate effusion had thick fibrinous organisation with evidence of effusive constriction. Only 10 patients were clinically suspected to have pericardial effusion during admission. Additional diagnoses in patients with pericardial effusion included five with congestive cardiac failure, four with pulmonary tuberculosis, and four with bacterial pneumonia. Four (13\%) patients with pericardial effusions died in hospital. None of the patients had clinical or echocardiographic evidence of infective or non-bacterial endocarditis.

\section{DILATED CARDIOMYOPATHY AND LEFT \\ VENTRICULAR DYSFUNCTION}

The demographic data on patients with dilated cardiomyopathy and left ventricular dysfunction is given in table 1 . Five $(83 \%)$ of six patients with dilated cardiomyopathy and eight $(73 \%)$ of 11 patients with left ventricular dysfunction had AIDS. Four patients with dilated cardiomyopathy had CD4 counts of 0 , 29,86 , and 130 cells $/ \mu \mathrm{l}$. Of the 14 patients with dilated cardiomyopathy 13 presented with features of congestive cardiac failure and cardiac failure was an incidental finding in one with lymphoma. Additional diagnoses in these patients included pericardial effusion in three and bacterial pneumonia in two patients. Of the 14 patients with dilated cardiomyopathy, five $(36 \%)$ died in hospital. Of the 33 patients with left ventricular dysfunction, $11(33 \%)$ had features of cardiac failure and $22(67 \%)$ did not. Additional diagnoses in these patients included bacterial pneumonia in six, pulmonary tuberculosis in four, miliary tuberculosis in three, Pneumocystis carinii pneumonia in two, and bacterial meningitis in two patients. Five $(15 \%)$ patients with left ventricular dysfunction died in hospital. For all patients with impaired left ventricular function (dilated cardiomyopathy and left ventricular dysfunction), left atrial size, left ventricular diastolic, and systolic dimensions were signifi- cantly larger in those with clinical features of cardiac failure than in those without (table 2). Left atrial size was significantly larger in those with dilated cardiomyopathy than in those with left ventricular dysfunction (table 2).

\section{Discussion}

This study showed that echocardiographic abnormalities are very common in acutely ill HIV infected patients in hospital in Zimbabwe. The commonest abnormalities were left ventricular dysfunction $(22 \%)$ and pericardial disease (19\%). While some patients with left ventricular dysfunction presented with features of cardiac failure, a large proportion, $(67 \%)$ had left ventricular dysfunction detected only by echocardiography without any prior clinical suggestion of heart failure. This finding has been observed in other studies. ${ }^{6715}$ Asymptomatic left ventricular hypokinesia detected by cross sectional echocardiography has been considered to represent either a mild form of non-dilated cardiomyopathy or the beginning of heart muscle disease that will eventually progress to dilated cardiomyopathy. ${ }^{7}$ Such progression has been demonstrated in some patients with increasing dilatation of left ventricular cavity size and the development of clinical congestive cardiac failure. ${ }^{715}$ In a pooled analysis of echocardiographic studies reporting on asymptomatic left ventricular hypokinesia the prevalence ranged from three to $41 \%$ with about $6 \cdot 2 \%$ eventually developing congestive heart failure. ${ }^{7}$ Studies have shown that HIV related heart muscle disease is often seen in a state of severe immunosuppression with low CD4 cell counts $(<100$ CD4 cells $/ \mu \mathrm{l})$ and poor prognosis. ${ }^{816}$ In this study a meaningful comparison of $\mathrm{CD} 4$ cell counts could not be made because these were available in only a few patients with myocardial disease, nevertheless, the counts were low in those in whom they were done. The HIV infected patients in this study presenting with dilated cardiomyopathy were clinically or echocardiographically indistinguishable from cases of idiopathic dilated cardiomyopathy often seen in Africa. ${ }^{11} 1217$

The pathogenesis of myocardial disease in HIV infection is not known in most cases. A review of several studies dealing with cardiac involvement in HIV infection ${ }^{18}$ has discussed the role of many opportunistic infections such 
as Toxoplasma gondii, cytomegalovirus, and Cryptococcus neoformans in the aetiology of HIV related myocardial disease. However, in a study of a large group of patients in the United Kingdom Toxoplasma gondii and cytomegalovirus infections were not shown to be major aetiological factors in HIV associated myocardial disease. ${ }^{6}$ Similar studies have not been carried out in Zimbabwe or in many parts of Africa where HIV infection is prevalent. Myocardial disease has also been attributed to direct HIV infection of the myocardium, ${ }^{1920}$ with a report of HIV being cultured from endocardial tissue..$^{21}$ Antiretroviral agents such as zidovudine have been implicated in the aetiology of cardiomyopathy ${ }^{22}$ but, none of our patients received these agents or indeed any other reported cardiotoxic drugs such as pentamidine or ganciclovir. ${ }^{23}$ Moreover, some studies have failed to demonstrate any association of cardiomyopathy and treatment with antiretroviral agents. ${ }^{6}$ Other factors implicated include selenium deficiency ${ }^{24}$ and tumour necrosis factor. ${ }^{25}$ The aetiology of myocardial dysfunction in HIV infection is probably complex and multifactorial.

Right ventricular dilatation may be secondary to a generalised myopathic process such as dilated cardiomyopathy or a consequence of pulmonary hypertension. In this study, 5/14 (36\%) patients had right ventricular dilatation as part of a generalised myocardial disease; however, $64 \%$ had isolated right ventricular dilatation occurring in the presence of severe respiratory disease, which implicated pulmonary hypertension in its causation. Some studies have shown the regression of isolated right ventricular dilatation when the pulmonary disease resolved. ${ }^{615}$

There is a wide spectrum of pericardial involvement in HIV infection ranging from asymptomatic effusions detected on routine echocardiography to fatal tamponade and constrictive pericarditis. ${ }^{13}$ Pericardial disease in HIV infected patients in Africa has been shown to be largely due to tuberculosis. ${ }^{1-3} \mathrm{~A}$ large increase in the number of patients presenting with pericardial tuberculosis in Zimbabwe has been attributed to HIV infection. A recent study showed that out of 57 cases of tuberculous pericarditis $38(67 \%)$ were HIV related. ${ }^{3}$ However, several other causes of pericardial disease have been identified including Mycobacterium avium-intracellulare, Cryptococcus neoformans, Nocardia asteroids, pyogenic organisms, Kaposi's sarcoma, lymphoma, viral infections, and possibly HIV itself. ${ }^{13}$

Infective endocarditis has been described in HIV infection, especially in the context of intravenous drug users. ${ }^{9}$ However, none of our patients admitted to intravenous drug use and no case of infective endocarditis was found. The marantic endocarditis seen in chronically ill and wasted patients ${ }^{26}$ was also not seen in our study patients.

We have shown in this study that cardiac abnormalities are common in acutely ill heterosexual HIV infected patients in hospital in Zimbabwe. There is frequently myocardial dysfunction, but this may be asymptomatic. The course of this asymptomatic echocardiographic myocardial dysfunction and its relevance to the overall long-term prognosis of these patients remains undetermined. Furthermore, studies of the aetiology and natural course of myocardial dysfunction in HIV infection is of interest because this may throw some light on the pathogenesis of "endemic" idiopathic dilated cardiomyopathy ${ }^{27}$ which is prevalent in Zimbabwe.

This study was supported by a grant from the University of Zimbabwe research board, number RB/61/93. Permission to publish was given by the Medical Research Council of Zimbabwe.

1 Cegielski JP, Ramaiya K, Lallinger GJ, Mtulia IA, Mbaga IM. Pericardial disease and human immunodeficiency virus in Dar es Salaam, Tanzania Lancet 1990;335: 209-12.

2 Taelman H, Kagame A, Batungwanayo J, Nyirabareja A, Abdel Aziz M, Blanche P, et al. Pericardial effusion and HIV infection. (letter) Lancet 1990;335:924.

3 Pozniak AL, Weinberg J, Mahari M, Neill P, Houston S, Latif A. Tuberculous pericardial effusion associated with HIV infection: a sign of disseminated disease. Tubercle Lung Dis 1994;75:297-300.

4 Cammarosano C, Lewis CW. Cardiac lesions in acquired immune deficiency syndrome (AIDS). $7 \mathrm{Am}$ Coll Cardiol 1985;5:703-6.

5 Anderson DW, Virmani R, Reilly JM, O'Leary T, Cunnion $\mathrm{RE}$, Robinowitz $\mathrm{M}$, et al. Prevalent myocarditis at necropsy in the acquired immunodeficiency syndrome. $f$ Am Coll Cardiol 1988;11:792-9.

6 Jacob AJ, Sutherland GR, Bird AG, Brettle RP, Ludlam CA, McMillan A, et al. Myocardial dysfunction in patients infected with HIV: prevalence and risk factors. Br Heart f 1992;68:549-53.

7 Herskowitz A, Vlahov D, Willoughby S, Chaisson RE Schuhnan SP, Neumann DA, et al. Prevalence and incidence of left ventricular dysfunction in patients with human immunodeficiency virus infection. $\mathrm{Am} \mathcal{F}$ Cardio 1993;71:955-8.

8 De Castro S, D'Amati G, Gallo P, Cartoni D, Santopadre P, Vullo V, et al. Frequency of development of acute global left ventricular dysfunction in human immunodeficiency virus infection. $\mathcal{F} \mathrm{Am}$ Coll Cardiol 1994;24:1018-24.

9 Corallo S, Mutinelli MR, Moroni M, Lazzarin A, Celano $\mathrm{V}$, Repossini A, et al. Echocardiography detects myocardial damage in AIDS: prospective study in 102 patients. Eur Heart $¥$ 1988;9:887-92.

10 Centers for Disease Control: Revised classification system for HIV infection and expanded surveillance case definition for AIDS among adolescents and adults. MMWR tion for AIDS

11 Gwata T. Cardiomyopathy in Rhodesia. Cent Afr 7 Med 1977;23:247-50.

12 Lutalo SK. Clinical progress of followed-up dilated (congestive) cardiomyopathy patients. Cent Afr $₹$ Med 1988 ; 34:21-5

13 Kaul S. Cardiac manifestations of acquired immune deficiency syndrome: a 1991 update. Am Heart $\mathcal{f} 1991 ; 122$ 535-44.

14 Sahn DJ, DeMaria A, Kisslo J, Weyman A. Recommendations regarding quantitation in M-mode echocardiography: results of a survey of echocardiographic measurements. Circulation 1978;58:1072-83.

15 Balanchard DG, Hagenhoff C, Chow LC, McCann HA Dittrich HC. Reversibility of cardiac abnormalities in human immunodeficiency virus (HIV)-infected individuals: a serial echocardiographic study. $\mathcal{F} \mathrm{Am}$ Coll Cardio 1991;17:1270-6.

16 Currie PF, Jacob AJ, Foreman AR, Elton RA, Brettle RP Boon NA. Heart muscle disease related to HIV infection prognostic implications. Br Med F 1994;309:1605-7.

17 Anonymous. Dilated cardiomyopathy in Africa. Lancet $1985 ; 1: 557-8$

18 Currie PF, Boon NA. Cardiac involvement in human immunodeficiency virus infection. $Q \mathcal{F}$ Med 1993;86: $751-3$.

19 Grady WW, Cheng L, Lewis W. Infection of the heart by the human immunodeficiency virus. Am f Cardiol 1990; 66:203-6.

20 Herskowitz A, Wu TC, Willoughby SB, Vlahov D, Ansari AA, Beschorner WE, et al. Myocarditis and cardiotropic viral infection associated with severe left ventricular dysfunction in late stage infection with human immunodeficiency virus. $₹$ Am Coll Cardiol 1994;24:1025-32.

21 Calabrese LH, Proffitt MR, Yen-Lieberman B, Hobbs RE, Ratliff NB. Congestive cardiomyopathy and illness related to the acquired immunodeficiency syndrome (AIDS) associated with isolation of retrovirus from myo(AIDS) associated with isolation of retrovitus

22 Herskowitz A, Willoughby S, Schulman SJ, Bartlett JD, Baughman KL. Cardiomyopathy in HIV infected paughman $\mathrm{KL}$. Cardiomyopathy in patients associated with antiretroviral therapy: 
23 Lewis W, Grody WW. AIDS and the heart: review and consideration of pathogenetic mechanisms. Cardiovasc Pathol 1992;1:53-65.

24 Zazzo JF, Chalas J, Lafont A, Camus F, Chappuis P. Is nonobstructive cardiomyopathy in AIDS a selenium deficiency-related disease. $\mathcal{F}$ Parenter Enter Nutr 1988;12: 537-8.

25 Matsuya T, Kobayashi N, Yamamoto N. Cytokines and
HIV infection: is AIDS a tumor necrosis factor disease. AIDS 1991;5:1405-17.

26 Garcia I, Fainstein V, Rios A, Luna M, Mansell P, Reuben $\mathrm{J}$, et al. Nonbacterial thrombotic endocarditis in a male homosexual with Kaposi's sarcoma. Arch Intern Med 1983;143:1243-4.

27 Jacob AJ, Boon NA. HIV cardiomyopathy: a dark cloud with a silver lining (editorial). Br Heart f 1991;66:1-2. 